\title{
Notas sobre el Control de Sociedades Anónimas en el Sistema de Derecho Anglo-Americano
}

\author{
por el Dr. FELIPE OSTERLING PARODI, \\ Catedrático de Derecho Internacional Privado
}

Para tener un concepto universal de las Ciencias Jurídicas es indispensable conocer los dos grandes sistemas de Derecho vigentes: el Derecho, de origen romano, que predomina en los países latinos، Y el Derecho Común o Sistema de Derecho Anglo-Americano, de origen inglés, que predomina en los países anglo-sajones.

Se ha expresado, con acierto, que el Derecho Romano empieza con un Código y termina con otro Código. Entre la Ley de las Doce Tablas y el Corpus Juris Civilis transcurrieron aproximadamente mil años durante los cuales nace; se desarrolla y perfecciona la obra de los legisladores y jurisconsultos romanos.

Paralelamente a la labor de los jurisconsultos, cuyos preceptos adquirieron obligatoriedad al ser sancionados por la Ley de las Citas, se desenvolvió en Roma la obra del legislador que codificó la doctrina y jurisprudencia.

Después de la caída del Imperio Romano de Occidente y de la desaparición del Imperio de Bizancio, declina el conocimiento y estudio del Derecho Romano hasta caer en el más completo olvido, sustituyéndolo las costumbres y leyes personales- de las tribus germanas.

Sin embargo, gracias a la labor de los glosadores y post-glosadores de los siglos XI, XIII y XIV, este sistema jurídico nuevamente se difunde por los países europeos, recogiéndolo diversas legislaciones $y$, en particular, el notable Código de Napoleón, fuente inmediata de numerosas codificaciones modernas.

El Sistema de Derecho Anglo-Americano no es obra del leqislador ni del jurisconsulto; tiene su origen en las costumbres de las tribus germanas $y$ se desarrolla en Inglaterra en forma sistemática $y$ permanente, con la influencia danesa y normanda, entre los siglos XII y XIV.

Sus preceptos han tenido singular repercusión en el derecho moderno, especialmente en el Derecho Constitucional, al consagrar la Carta Magna y la Petición de Derechos el principio, transcrito por la Constitución de los Estados Unidos de Norte América, que ninguna cersona será privada de su vida, libertad, propiedad o derechos, sin un debido proceso legal.

No obstante que la base de la organización jurídica del Sistema de Derecho Anglo-Americano es autónoma e independiente del Derecho Romano, su estructura no fue impermeable a este sistema, particularmente en el compo del Derecho de Sucesiones $y$ del Derecho Mercantil. 
El distinto origen y evolución de ambos sistemas; el hecho que el Sistema Romano se fundamente en la interpretación del derecho codificado, machas veces con normas rígidais que no pueden dejar de ser aplicadas, Y que el Sistema Anglo-Americano sea elaborado en las decisiones judiciales, en la aplicación de principios cuya flexibilidad depende del supuesso de hecho; $\mathrm{y}$, particularmente, las exigencias de la actividad humancs regulada, han sido las causas determinantes que ciertas materias, en cada sistema, hayan adquirido mayor perfeccionamiento.

Si bien es cierto que la técnica legislativa latina, con su bagaje histózico, supera en muchos aspectos al Derecho Común, en algunas ramas de las Ciencias Jurídicas, sensiblemente, los preceptos legales no han marchado paralelos $\alpha$ la actividad normada, encontrándonos con disposiciones que han devenido anacrónicas e inaplicables dentro de las modernas concepEiones de la Teoría General del Derecho.

Posiblemente es en el campo del Derecho Mercantil y, concrevumente, en las sociedades anónimas, materia dinámica por naturaleza, que las normas codificadas y su estática interpretación son insuficientes para regular con precisión, con garantía y de acuerdo al ritmo de la vida moderna -concepto fundamental si consideramos que el Derecho está referido, esencialmente, a las contingencias etnográficas, físicas y morales de un pueblo- las relaciones jurídicas.

Merece especial consideración, en esta materia, un problema desarrollado con minuciosidad y madurez en el Sistema de Derecho Anglo-Americano y que ha sido totalmente silenciado, por la antiguiedad de sus disposiciones, por el Código de Comercio Peruano del año 1902. Nos referimos al control de sociedades y a las relaciones entre las compañías controladoras o matrices y las sociedades subsidiarias.

Es necesario tener presente, al analizar estos conceptos, que en el Sistema de Derecho Anglo-Americano, a diferencia del Sistema Latino, el contrato de Sociedad Anónima es, por naturaleza, la reunión de dos o más personas con el objeto de realizar un fin pecuniario, más no lo es por esencia, como en el Derecho Latino, pues también es permitida la constitución y funcionamiento de una compañía con una sola persona, quien aporta la totalidad del capital y es propietaria de la integridad de las acciones, con el doble objeto de limitar su responsabilidad y otorgarle la duración indefinida de la que carecen las personas naturales, desconociéndose, por otra parte, las acciones al portador, pues sólo son permitidas las emisiones de acciones nominativas.

Una sociedad subsidiaria, genéticamente, es aquella en la que otra compañía, denominada controladora o matriz, es propietaria de una mayoría de las acciones, teniendo, por consiguiente, su control.

Sin embargo, no siempre es necesario para controlar una sociedad, que la compañía matriz sea tenedora de la mayoría de sus acciones; con frecuencia la propiedad de una minoría de dichas acciones permite el ejercicio de un control mediato, en particular en aquellas sociedades en las que se efectúan importontes emisiones de acciones, siendo suficiente ser propietario del $20 \%$ ○ $25 \%$ de la totalidad de acciones emitidas para que el control mediato devengue en absoluto. 
Existen, en consecuencia, dos formas de control de sociedades: el inmediato, que se ejercita con la tenencia de la mayoría de las acciones de la compañía subsidiaria o controlada por la sociedad controladora o matriz; y el mediato, en que la compañía controladora $\circ$ matriz, que tiene tan sólo una minoría de las acciones de la sociedad subsidiaria, ejercita un control absoluto en las siguientes formas:

a) A través del voto cumulativo. Cuando se debe elegir al Directorio de la Compañía puede el votante acumular sus votos en un sólo Director. Así, en una sociedad anónima que tiene 4 Directores si es propietario de 100 acciones puede votar en la forma siguiente:

100 votos por 100 acciones para cada uno de los Directores; 200 votos para cada uno de sólo dos Directores; $y$, finclmente, acumular 400 votos en favor de uno de los Directores, evitando, de esta manera, su dispersión.

b) Mediante una comisión de confianza en virtud de la cual un determinado número de accionistas, propietarios de una contidad suficiente de acciones como para constituir mayoría, las entregan a un fideicomisario o consignatario, con todos los derechos a ellas inherentes, excepto los de cobrar dividendos o autorizar fusiones, disoluciones o liquidaciones.

Este caso se presenta, frecuentemente, cuando una sociedad en mala situación económica acude a un inversionista $y$ éste impone como condición, para aportar el capital que va a tonificar a la empresa, que una mayoría de las acciones de la compañía se entreguen irrevocablemente, por un determinado período de tiempo, a un fideicomisario, que seguirá las instructivas del inversionista, quién, en última instancia, va a ejercitar un control absoluto sobre la empresa.

c) Mediante el voto por poder. Un accionista minoritario de la compañía puede obtener la representación de la mayoría de las acciones para votar en las Juntas de Accionistas, quedando a su libre arbitrio, en consecuencia, la elección del Directorio.

d) Por el acuerdo entre diversos accionistas minoritarios, propietarios, en conjunto, de un número suficiente de acciones como para formar mayoría y actuar en bloque ejercitando un control absoluto sobre la empresa.

Pero es evidente que el control inmediato, aquel que se ejercita con la propiedad de una mayoría de las acciones, constituye la forma clásica del gobierno de sociedades en el Sistema de Derecho Anglo-Ámericano.

Estos casos no significan que se destruya la identidad legal de cada compañía, o que la sociedad subsidiaria actúe como mandataria de la controladora, o que exista una fusión entre ambas para formar una nueva persona jurídica.

Sin embargo, cuando la compañía controlada es un simple instrumento de la matriz, organizada con el propósito de burlar a los acreedores, do eludir responsabilidades o de no acatar las leyes contra el monopolio, se prescinde del aspecto formal y las responsabilidades de la sociedad subsidiaria son de cargo único $\mathrm{Y}$ exclusivo de la compañía controladora.

Dos son pues los aspectos del control de sociedades que la jurisprudencia en el Sistema de Derecho Anglo-Americano ha regulado con abso- 
Iuta nitidez: el fraude $Y$ el monopolio. Ámbos extremos se ilustrarón con ejemplos.

Si una compañía minera, constituída con un capital social de USS 10,000.000.00, requiere en la explotación de sus minas emplear explosivos que importen un gran riesgo para su personal, podría constituir una compañía subsidiaria o controlada, con un capital social de US\$5,000.00, que efectuaría dichos trabajos, limitando sus responsabilidades frente a los servidores de esta nuevá empresa y $\alpha$ los terceros, hasta por la indicada suma de US\$ 5,000.00.

En caso que se produjera un accidente que exigiera responsabilidades superiores a su capital, esta compañía subsidiaria, constituída con propósitos fraudulentos y tan solo revestida de fórmulas legales, respondería con el íntegro de su patrimonio, cubriéndose todo exceso con el patrimonio de la compañía matriz.

En la hipótesis propuesta los servidores de la empresa o los terceros perjudicados tendrían acciones directas contra ambas compañías. Pero la acción también puede corresponder al Estado.

En efecto, aproximadamente hasta el año 1920 la Compañía Petrolera Standard Oil operaba en gran parte del territorio de los Estados Unidos de Norte Ámérica mediante el sistema de sociedades matrices y subsidiarias, que le permitía controlar, en forma casi absoluta, el mercado petrolero de ese país. En virtud de la legislación contra el monopolio, todas estas compañías tuvieron que independizarse, funcionando en la actualidad como entidades absolutamente distintas, con diferentes accionistas y administradores, no obstante que conservan denominación similar, que tan solo se diferencia por el nombre del Estado en que actúan, existiendo, en tal virtud, las Compañías Standard Oil de New Jersey, Standard Oil de California, Standard Oil de New Orleans, etc.

Sin embargo, en muchas de las relaciones entre las compañías controladoras y subsidiarias la jurisprudencia se encuentra vacilante, como consecuencia de la pluralidad de jurisdicciones existentes en los Estados Unidos de Norte América, ya que son los Jueces Estatales, y nó los Federales, competentes para conocer del 'asunto, contrariamente a los casos de monopolio, a que se refiere el ejemplo antes propuesto, cuyo conocimiento corresponde al Gobierno Federal que, a través de la Corte Suprema, ha expedido resoluciones uniformes.

En algunos casos las Cortes han encontrado una relación de mandante $y$ mandatario entre las compañías controladora $y$ subsidiaria. En otros las compañías matrices han respondido por las responsabilidades dorivadas de los contratos y deudas de sus sociedades subsidiarias, no obstante no haber existido fraude. Las Compañías controladoras también han llegado a ser condenadas, sin haber existido fraude, por los actos ilícitos originados por negligencia de la sociedad subsidiaria. Algunas veces los bienes de las compañías controladas han sido considerados como bienes de la matriz, que se encontraba en estado de falencia, $y$ han sido ejecutados por los acreedores de ésta. Otras veces se ha propuesto el problema de si la sociedad controladora puede cobrar sus créditos, conjuntamente con los demás acreedores, a la compañía subsidiaria. Este criterio ha sido re- 
chazado, aduciéndose que las inversiones fueron efectuadas por la compañía matriz en su propio negocio, hecho que no puede perjudicar a terceros, siendo ilógico, por otra parte, que se ejecute un crédito contra sí misma.

Podemos afirmar, en conclusión, que las responsabilidades están determinadas por la buena fe y honestidad con que se procedió. Si una compañía controla a otra para salvaguardar sus intereses y su patrimonio, con perjuicio de terceros o afectando el orden público, es necesario imponer restricciones que, generalmente, se traducen en responsabilidades pecuniarias.

En los casos en que no concurren estas circunstancias, el simple hecho que las acciones de una compañía sean propiedad de otra, no significa, de ningún modo, que la sociedad subsidiaria sea un simple departamento, fideicomisario o mandatario de la compañía matriz o de sus accionistas.

Debemos analizar, en este estudio, las diferentes responsabilidades. a que estón sujetas las compañías que controlan inmediatamente, 0 sea por mayoría de acciones, y las que controlan mediatamente, por los cuatro sistemas antes referidos, respecto a los actos o contratos de las sociedades controladas o subsidiarias con terceros.

Si la Compañía A controla mediatamente a la Compañía B y ésta consti:uye una compañía subsidiaria denominada C., a la que va a controlar inmediatamente, es decir por mayoría de acciones, por las responsabilidades derivadas de los actos ilícitos o del incumplimiento de las obligaciones contractuales de $\mathrm{C}$ puede responder $\mathrm{B}$, según el Tribunal que conozca del asunto, con todo su patrimonio, más no los accionistas de $B$, entre sllos la sociedad $A$, que tan sólo controla a ésta mediatamente, como accionista minoritaria. El ejemplo se basa en el supuesto que en ninguna de estas relaciones jurídicas haya existido fraude.

Si variando la hipótesis la Sociedad B constituyó fraudulentamente la Compañía C, a la que controla inmediatamente, por mayoría de acciones, por las responsabilidades de esta sociedad C. respondería, ineludiblemente, ante cualquier jurisdicción, la Compañía $B$, y aún sus propios accionistas, entre otros la sociedad $A$, con todo su patrimonio, pues en este caso no se respeta la limitación en la responsabilidad de los accionistas que, procediendo fraudulentamente en los acuerdos de la sociedad B, constituyeron la Compañía C.

Es decir, que se consagra un principio idéntico al contenido en el Derecho latino: por las obligaciones de una compañía, conforme a las limitaciones impuestas por la naturaleza jurídica del contrato de sociedad anónima, tón sólo ella es la responsable, con todo su patrimonio, pero si existiere fraude la responsabilidad alcanza, personalmente, a todos sus accionistas.

La situación es diferente si el control de todas y cada una de las Sociedades se efectúa en forma inmediata. Así, si la Compañía $A$ controla inmediatamente a su compañía subsidiaria B y ésta, a su vez, actúa como controladora inmediatá de C, la que controla, también inmediatamente, a $D$, ésta última Sociedad estaró, en última instancia, controlada por la Com- 
pañía $A$, que vendría a constituir, expresándonos gráficamente, el vértice de una pirómide.

En estos casos, si no ha existido fraude, por las responsabilidades. derivadas de los actos ilícitos o del incumplimiento de las obligaciones cantractuales de la Sociedad D frente a terceros, pueden resultar responsables, con todo su patrimonio, las compañías C, B y A, según la jurisdicción que sea competente para conocer del asunto. Pero en el caso de haberse procedido fraudulentamente, la referida responsabilidad de las sociedades $C$, B y A, y aún de los propios accionistas de $A$, sería inevitable, cualquiera que fuere el Tribunal que conoce del asunto.

Fácilmente se advertirá que todas las hipótesis antes estudiadas se basan en el supuesto que el accionista haya tenido acceso a una compañía, sobre la cual puede llegar a ejercitar, por mayoría de acciones 0 en forma mediata, un control absoluto.

Pero cuando una Compañía advierte el peligro que importa la intromisión de accionistas, que pueden pretender su control o el simple conocimiento de operaciones que, por su carácter, tienen la condición de secretas, hasta que punto tiene el derecho de limitar estatutariamente la libre trasmisión de sus acciones?

Este caso ya ha sido resuelto en el Perú por una ejecutoria de lat Corte Suprema.

En el juicio seguido por "El Pacífico", Compañía de Seguros, y la señora Mercedes Gallagher de Parks contra la Compañía de Seguros "Rimac", se demandó la inscripción en los libros de transferencias de ácciones de esta última compañía, de la venta de 1,440 acciones nominativas que la señora Gallagher de Parks había efectuado en favor de "El Pacífico", Compañía de Seguros, y la nulidad del artículo $8^{\circ}$ de los estatutos de la Compañía de Seguros "Rimac" que concedía al Directorio la atribución $y$ le imponía el deber de calificar, en votación secreta, las transferencias de acciones que efectuaran los socios de la Compañía.

Se trataba, en consecuencia, de la intromisión de una empresa competidora que hubiera podido originar la elección de sus propios Directores, con acceso a los libros, negocios y operaciones de la Compañía de Seguros "Rimac", y con el peligro potencial del control mediato.

La Compañía de Seguros "Rimac" defendía un principio ético indisputable en resguardo del normal desenvolvimiento de sus actividades, $Y$ así lo consideró la Corte Suprema al consagrar la validez de dicha clóuusula restrictiva.

En el sistema de Derecho Anglo-Ámericano el punto permanece dudoso. Pero es evidente que su validez debe ser referida al caso concreto: inobjetable al actuar en resguardo de la vida misma de la Compañía y sin efecto legal alguno si el Directorio, al aplicarla, cometo un abuso del Derecho, violando el principio Constitucional de la libre contratación. 